\section{Uterine Prolapse, Mobile Camp Approach and Body Politics in Nepal}

\section{Madhusudan Subedi}

\section{Abstract}

Various studies show that more than 600,000 women in Nepal are suffering from prolapsed uterus and that 200,000 of those needed immediate surgery. Many of the women with prolapse could recall the exact moment they first felt the prolapse and found difficulty to share the problems due to fear of stigma. Stories ranged from seven days immediately after the first delivery to after the birth of the fifth or sixth child; during cooking rice to sneezing and long coughing; fetching water in a big bucket to working in the field. If detected at an early stage, uterine prolapse (UP) can be controlled by pelvic exercises. For severe cases, the remedy is to insert a ring pessary to stop it from descending which has to be changed every four months. In extreme cases, uterine tissue protrudes from the vagina causing extreme discomfort. The only remedy is hysterectomy in which the uterus is surgically removed. The operation costs are about NRs 20,000. The Government of Nepal and other donor organizations have allocated funds to provide services to about 10,000 to 12,000 women suffering from uterine prolapse as humanitarian support each year and services are likely to be expanded in future. Women suffering from UP have not been able to get benefit from such assistance due to deep rooted sociocultural perceptions and practices. The number of suffering women, on the other hand, would not decrease from existing curative management policy without hammering the root causes of UP. Moreover, a clear vision and strategy is needed to shift from humanitarian aid to a more sustainable public health intervention.

Keywords: Camp Approach, Humanitarian Aid, Socio-cultural Practices, Sustainable Policy, Uterine Prolapse

\section{Introduction}

Although the women's health agenda has been largely defined by biomedicine and public health, anthropology has much to offer in terms of defining and understanding women's health from the perspective of women themselves (Inhorn, 2006). And the health problems, be it among men or women, cannot be separated from the larger social, cultural, economic, and political forces that shape and constraint human life. This paper examines the prolapsed uterus, one of the major reproductive health problems of women in Nepal, and the short term camp approach, perception of UP and different body part of women in the local context. Furthermore, it also tries to offer some policy issues for sustainable public health intervention.

UP is a condition in which a woman's supportive pelvic muscles, tissues and ligaments break away from the body's internal structure and the uterus, rectum, or bladder drops into or out of the vagina. The condition is mainly due to insufficiency of the pelvic floor and consists of herniation of an adjacent pelvic organ into the vagina.

UP is usually classified into 4 anatomical stages, corresponding to the severity of the condition. For the first stage, the uterus leaves its place but is still inside the vagina. In the second stage, the uterus leaves its place and comes up to the opening of the vagina. For two lower stages (I and II), conservative management including pelvic floor muscle training or ring pessary insertion are considered the best options (UNFPA and Sancharika Samuha, 2007). A ring pessary is a plastic or rubber device that is inserted into the vagina, which holds the uterus. After a health worker inserts this into the vagina, there is no need to do anything for three months. Every three months, it has to be taken out, cleaned properly and inserted back after boiling in hot water. If a woman becomes pregnant while the pessary is inserted then it must be taken out in a health institution. The ring pessary cannot hold the uterus in a situation where the uterus is fully out.

When the uterus comes out of the vagina, a woman must bring herself to a hospital, and she should be treated through surgical procedures. Trained doctors can remove the uterus through 


\section{4 | Madhusudan Subedi}

surgery. Mostly these surgeries involve surgical removement of the uterus and subsequently a pelvic floor repair. After the surgery, women will be able to perform their normal work, but will not be able to undergo menstruation or become pregnant.

For the most part, Nepal adheres to traditional gender roles where women are not always able to make independent decisions about their reproductive health. But families and communities still refuse to speak about the disease and it is often a secret kept within the home (UNFPA and Sancharika Samuha, 2007). The causes and consequences of the problem as perceived by women suffering from UP, government initiative to address this issue, and sociocultural practices regarding UP will be discussed in the following sections.

\section{Methods and Materials}

This research was conducted by the article's author during mobile camps operated by ADRA Nepal in Jumla, Bajura, and Achham districts, and by PHECT-Nepal in Salyan district. Although the objective of field visit was to conduct final evaluation of the mobile health camp projects implemented by ADRA and PHECTNepal, the author being an anthropologist, collected additional information regarding socio-cultural issues of UP and ethnography of mobile camp. These issues are pertinent but were beyond the scope of evaluation of the project.

Interaction with the women suffering from UP was done in detail to find out the social and cultural practices regarding reproductive and sexual health issues. Such interactions were conducted in an exploratory fashion, mainly by generally asking about the health situation of their locality and subsequently shifting to women's general health problems. Slowly the interaction concentrated on the illness the women generally suffer from. The informants were further probed to discuss on UP issues. Focus group discussions (FGD) with women and men, interactions with the mobile health camp team and local health workers working at the concerned health facilities were also conducted to validate the information and get more insight regarding UP related issues. Men were included in the study in order to achieve community perspectives.
Moreover, a series of interactions were done with the women who were waiting for surgery and who had undergone surgical correction at Nepalganj Medical College Teaching Hospital (NMCTH), Kohalpur. Though there are issues related to quality of care, management at the camp sites and at the hospital, the paper is limited to causes, consequences and cultural perceptions regarding UP. This does not mean that quality of care and process management issues are less important. This, however, belongs to another paper.

\section{Results and Discussion \\ 3.1 Prevalence of Prolapsed Uterus}

The global prevalence of prolapsed uterus ranges from 4 to 40 percent (UK APPG, 2009 cited in Pradhan et al., 2010). Studies in Nepal have shown varying prevalence for Nepal. A study conducted by Bonetti et al. (2002) in Far Western Nepal revealed that 25 percent of the visitors to free female health care clinics were diagnosed with UP. In their study in Bhaktapur, Marahatta and Shah (2003) found that prevalence of UP in women aged 20 years and above was 8 percent. Another study (Tuladhar, 2005) conducted in Bajhang district found that 51.6 percent of the visitors to a medical camp for women had gynecological problems, of which 36 percent accounted UP.

The 2006 Nepal Demographic and Health Survey (NDHS) found that up to 7 percent of women of reproductive age (15-49 years) were suffering from UP. A study of reproductive morbidities done by The Institute of Medicine and UNFPA (2006) among a representative sample of 2070 women from rural and urban, hilly and terai areas in 8 districts showed a 10.4 percent prevalence of UP. This study estimated that 600,000 women in Nepal suffer from UP, the majority of these women are of reproductive age and about 200,000 women are eligible for curative surgery (Institute of Medicine and UNFPA, 2006). Among them, 25.2 percent were below the age of 35 years, including 2.8 percent in the adolescent age group (15-19 years). Women above 30 years were the most vulnerable, 45.1 percent among them having UP. Among women 20 years and below, 14 percent had UP for the fist time. Among 30.4 percent of the women, UP was first noted after the first 
delivery, 44.9 percent noted after second and third deliveries. The mean years of suffering from UP was 7.89 years. Among them, 4.3 percent had suffered for 21-30 years.

Unlike in the developed world where UP is commonly seen in the postmenopausal age group unrelated to childbirth, UP in Nepal was found in younger population (14 percent before the age of 20, 44 percent at the age of 20-29 and the rest, 45.1 percent, after the age of 30). The mean age for prolapsed uterus occurrence was found to be 27.91 years, which significantly shows long years of suffering from UP beginning at relatively younger age.

Unlike our firm belief that UP is more common in hilly region, this study showed that the prevalence of UP was higher in the terai districts. Among the reproductive health problem diagnosed women, UP problems were found to be 44.5 percent and 27.6 percent from Rautahat and Saptari respectively. In Dadeldhura, the prevalence of UP was 17.7 percent. Thus, the study findings clearly show that UP is a serious public health problem in Nepal, in all ecological zones and development regions. High prevalence of UP is a symptom of a larger problem concerning reproductive rights and access to education and information.

\subsection{Causes of UP}

Marriage is assumed to be a basic, vital and fundamental institution not only for the physical, mental, spiritual, and social comfort of the spouses, but for the maintenance, protection, and education of the progeny. After marriage, the wife lives in the husband's home, and she has to consider the husband's family also as her family. She must, therefore, adjust herself to the changed situation after her marriage. She has to look upon her mother-in-law and father-inlaw as her own mother and father. Thus, the marriage is a sacramental process whereby the woman is transferred as a gift from one household to another. Motherhood is one of the carvings of a normal woman. No authority needs to be cited to support this philosophy (Uberoi, 1996). Parties enter into marriage alliances on the assumption that they will become father and mother in due course of time (Subedi, 2001). Having children is one of the principal aims of marriage, it is assumed that women have an

\section{6 | Madhusudan Subedi}

innate desire for motherhood, which in the proper course should be satisfied, that men too have a deep, although more culturally grounded, desire for parenthood, and that the joint procreation of children cements and reinforces the conjugal bond. It is a more common experience that the birth of a child, preferably a son, puts an end to minor misunderstandings and bickering between spouses, for the parties concentrate on lavishing in a common love of the child and thus is brought together. Contrariwise, a wife who is not prepared to become a mother at the cost of her youth, or who aborts a fetus against her husband's wishes is imputed to be unnatural, irresponsible, and cruel.

In Nepal, level of awareness regarding the need to rest before and after childbirth is very low. The mother-in-law, generally, shares her events during delivery days of her babies. They generally feel that birth is normal and there is no need for special arrangement before, during and after the delivery. Such attitude hinders the need and importance of institutional delivery, importance of rest after delivery, and minimizing physical work immediately after the delivery. Furthermore, such situations within the family discourage pregnant women to prevent UP.

During FGD many women shared with us stories such as, "many mother-in-laws still tell their daughter-in-laws that her first birth was given in the jungle when she was collecting grass and firewood for household use. The second birth was given when planting rice or millet in the field, and the third birth was given when she was in the market to buy household goods”. The ultimate message shared is that there is no need for rest before and during delivery. They further mentioned that young family members have been more aware about the importance of antenatal care and institutional delivery. However, due to household work, the practices of firewood to be collected from the forest, water to be collected from long distances due to unavailability of tap water in or near the household, and due to lack of supportive family members, many women are forced to work immediately after delivery.

Women in Nepal carry heavy loads after child birth, work strenuously and cannot maintain a nutritious diet. A large number 
of child birth or spacing successive child births too close to each other, giving birth at a tender age, lack of nutritious food during pregnancy and after child birth, unsafe abortions, applying pressure before the delivery stage, pressing of the lower abdomen after child birth, weakening of the pelvic floor where the uterus rests, separation of the pelvis from the pelvic floor while giving birth, child-birth using tools, giving birth to a large baby through the vagina, attempts to give birth by pressing the stomach in longer duration of the delivery period, continuously coughing after child birth, applying more pressure than required before the time of child birth, lifting heavy objects after child birth, malnutrition, dysentery for a long period, lack of blood, and lack of rest after child birth, all are some of the causes of UP stated by research findings (Bonetti et al., 2004; Bodner-Adler et al., 2007; Dangal, 2008; Schaaf et al., 2007) and mentioned by gynecologists. Many of these conditions are common in rural Nepal.

\subsection{Women's memories of First Events of Uterine Prolapse}

Almost all women were reluctant to share their first memories of events of UP. It was, I guess, probably because they had problems with sharing such experiences in front of a male. After informal discussions about the causes of UP, and also telling them about similar problems in other districts, they started to be open to share their memories. They were, however, also concerned about their identity in the stories that would be written about them. It was assured that their privacy would be strictly maintained. Then they shared their first memories openly.

"After 7 days of birth of my child, I had to cook food, fetch water and take care of cows and buffalos. My uterine could not tighten after giving birth. One day when I was carrying water in a gagri (cupper vessel) from the public tap my uterine muscles loosened, causing womb to fall slightly. With each successive pregnancy and continuous heavy work - farming, fetching water, collecting firewood and fodder - the problem got worse. After my sixth delivery, the whole uterus came out", said a 42 years old woman in Salyan. She further mentioned, "I was too shy and did not tell anybody. I used to push it back into my body”. A woman of aged 35 years in Bajura said, “ after two weeks of my second delivery, I

\section{8 | Madhusudan Subedi}

had gone to forest to collect daura (firewood) for cooking food. After returning from forest with the heavy load of firewood, I suddenly felt that my uterus was falling down with pain.” The story of another woman from Achham is also not that much different. A woman of 45 told that "when I was 16, I gave the first birth, but the child survived only 15 days. Next year I gave the second birth. The baby survived only one year. The third delivery was a son who is now 25 years old. After my fourth delivery, I felt weak. I was very thin. One day, I was climbing the tree to collect the fodder and I felt uneasy. I was sweating. Later it fell”. A 32 years old woman in Salyan said, “ I had just given birth to my first child and was working in the fields near my village. Suddenly I felt as if my insides were dropping out of me. I told no one - not even my husband - hoping the problem would go away”. Many women shared similar stories. A feeling of heaviness in the lower abdomen, pain in the lower abdomen were other memories of UP. They could not share their problems even with their husbands due to fear.

\subsection{Consequences of Uterus Prolapse}

The women were hesitant to discuss especially their UP problems, due to shame and humiliation. Many women fear condemnation from their communities and families, and discussion and debate about the disease do not openly occur within the family and in society. Women who suffer from UP continues to remain silent on the matter.

Many women shared with us that they faced urinating difficulties, tallo pet duckhne (lower abdominal pain), seto ganaune pani bagne (foul smelling white discharge). Other difficulties mentioned were lifting, standing, walking, and painful intercourse. Women suffering from second or third-degree uterine prolapse were unable to walk or stand. A 49 years old woman in Jumla told: " I did not have enough food. I didn't go to the doctor. My uterus kept falling out and I suffered a lot. I could not move, and I was in pain while working. My husband started to beat me and threatened to take a second wife. My mother-in-law thought I was not working well enough". She further said, "the health post was a 2 hour walking distance from my house. I had visited there previously for stomach 
pain and a wound. I had difficulty to walk, and had abdominal pain due to UP, but I did not discuss the curability of my misery of a prolapsed uterus". Feeling ashamed to share their reproductive health problems to the health workers was found to be very significant. Some women mentioned that they had relatively good relationship with their husband. They were blaming their fate. Some women, however, also mentioned that they were abused by their husband; some had even threatened to take a second wife.

This debilitating condition exposes the women to rejection by their husband, family, and sometimes even by the community. As a result they are completely deprived of their rights to participate in society, including in the community's development activities. Responding to the consequences of UP, the RH expert from UNFPA who had been coordinating the mobile camp said: "the consequence of UP is very pathetic. It is cheaper for a man to leave his wife and marry again. I have heard such stories in far-western mountain districts. Insulting women because of prolapse is very common". These examples provide enough documentation for the urgent need to study UP related social stigma and develop appropriate health education and promotion materials to prevent UP.

Almost all interviewed women were unaware that treatment was available. The women who had undergone surgical correction, told us at the NMCTH that they would routinely push the uterus back in place, to have it drop out again when coughing or sneezing. In Achham I also noticed that the women with UP problems are called Dhauki, a term used to dehumanize women suffering from UP. Research findings conducted in Nepal show that such deprivation has great consequences (Bonetti et al., 2004).

\subsection{Camp Approach: Experimentation and Learning}

Camp approach has been used in Family Planning and for Cataract operation for many years in Nepal. Since 2005, reproductive health services (including family planning, emergency obstetric care and treatment for prolapsed uterus) have been delivered in remote areas through mobile reproductive health camps. Camp approach for RH means that additional services related to $\mathrm{RH}$ are provided to the

\section{0 | Madhusudan Subedi}

marginalized, underserved, and conflict affected people in Nepal on a special day with the help of experts coming from higher levels in the health system or outside it. The camp approach includes information, education, and communication (IEC) activities to generate demand and provision of high quality services closer to the community.

The Government of Nepal (GoN) has recognized uterine prolapse as a high priority condition and has shown its commitment by creating a fund for provision of free uterine prolapse surgery services to women in need. The GoN has provided funds for the free surgical uterine prolapse treatment for about 3000 women per year. In support of this, reproductive health mobile camps are organized periodically with support from UNFPA and donors like ECHO, and the Danish, British, and Japanese Governments. During the camps, patients are screened for UP and severe cases are sent to the designated hospital where a team of specialists conducts the operations. The surgery and medication is free of charge and each patient, with one attendant, is provided travel and food expenses. These services are likely to be expanded in the future. However, a clear vision and strategy has not been adapted to shift from humanitarian aid to a more sustainable public health intervention owned by the government. The following paragraph provides a glimpse of the mobile health camps.

The long-term objective of the mobile health camps is to improve the reproductive health, protection, and self-sufficiency status of the most vulnerable population. The immediate objectives of camps are to increase utilization of RH and general health services to vulnerable populations; ensure delivery of essential RH services through mobile outreach health camps to women, men and adolescents; strengthen delivery of RH care through the primary health care approach ensuring essential medical supplies and $\mathrm{RH}$ kits; and increase knowledge for positive behaviors in order to increase demand for quality RH services.

The date and place of camps to be organized are, generally, decided by the consensus of district based stakeholders. Information about the camp days and places are provided to the people in the respective districts from different sources, ranging 
from Female Community Health Workers (FCHV), Youth Clubs, Mothers Group, pamphlets, posters and from local FM radios. On the camp day, various camp management activities are conducted in a very systematic way. The registration counter can be seen near the entrance gate. Here the health workers fill out a specially designed camp sheet for each case. This form includes basic sociodemographic information that is given at the registration. Volunteers guide each patient to the appropriate room for history taking.

The second counter is for history taking and general examination. Here the local health facility staff or junior health staff takes a detailed history about the person and fill it in the form. The history includes obstetric, menstrual history, and major complaints. The doctor or the nurse also does general examination including weight, pulse, blood pressure, clinical checking for Anemia or Jaundice. S/he explains to the clients about internal examination and also motivates them for undergoing vaginal and abdominal examination. If the client refuses, then the treatment is given on the basis of the symptoms only. If the client agrees, she is sent for detailed examination. This is done by the doctor.

The third station is for internal examination. It is located in a separate room with provisions made for privacy. The doctor carries out her vaginal and abdominal examination after reviewing the history of the client. Common problems such as RTI, prolapse etc., if found, are demonstrated to the nurses or the health staff working at the local health facility as part of their training by the medical doctor. The doctor prescribes the medicine and briefly explains the management to the clients. If required, the client is referred to the laboratory for simple test such as Hemoglobin and urine tests. After doing the lab test the client returns to the specialist for further consultation and treatment.

The next station is for counseling and guidance to explain to the patient the details of her problems and how to take medicines and further preventive measures. This is done by the health educator, public health nurse or RH counselor. Cases who need further treatment at a higher level such as operation for prolapse are referred to the appropriate level of services by giving them a

\section{2 | Madhusudan Subedi}

written referral slip. Finally the clients go to the dispensing counter to collect the medicines prescribed. The camps provide free medicine especially for women's RH problems.

An exhibition is also set up for providing health education on various aspects. The clients can see the exhibition while they are waiting to be examined by the specialists. Clients' relatives can also see the exhibition while they are waiting. The IEC activities include poster and pamphlets, pictorials, interaction and a targeted media campaign, video show, and street drama.

All the staffs are given specific duties during the camp. For example, the ANM and Nurses take the history and assist during the internal examination. Local volunteers help registration, help in weighing, provide health education, and help in general arrangements. The health educator provides health education to women who are waiting. The clients' attendance at the camp depends on the season, agricultural work, and also publicity.

The camp ends with a review meeting where the problems related to the organization of the camp, the type of cases seen and the follow up required, any difficulties faced and lesson learnt are discussed among the team members. Some implementing partners arrange experience sharing meeting with the local health facility staff and the community people separately to listen their impression about the camp activities.

The UP cases requiring surgical correction are referred to tertiary care centres. Most of them are managed by NMCTH. It has become a referral hub for surgical correction for UP cases for almost all funded projects in the Mid Western and Far Western regions.

However, no mechanism is developed for post-discharge consultation or responsibility for the patients who underwent surgical correction. After surgical correction and due stay at hospital, some faced difficulties while returning home because they had to travel long distances from Nepalganj to their respective districts. Some of the patients mentioned having complications such as pain and infections in the operated areas and had to consult and make purchases at local pharmacists. 
When inquiring at local health facility about the women who were referred for the surgery and about complication faced after surgery, it was found that the information regarding such issues were not provided by the implementing partners. People from the District Health Office (DHO) had visited the mobile camps, but it was just informal visits. A clear-cut monitoring/information system to keep track of these patients who have undergone surgical procedures, especially the ones who could face complications, seem to be absent.

Many people had positive responses about the camps in all the places visited during this study. "Camp approach has provided an opportunity for women to break their 'culture of silence' about various reproductive health problems. Women have started to share their $\mathrm{RH}$ problems with their neighbors, relatives and health facility staff", said a local teacher in Jumla. Another teacher mentioned that the camp approach is like a 'buffet party in a good hotel' or 'catering services during feasts', and varieties of technical experts including health educators are available. People also get a chance to watch RH related documentaries, participate in the drama, eat, and talk with outsiders. Once the camp is over, nothing will remain; people have to survive as usual. On the other hand, a FCHV in Salyan who was working for camp management said, "The camp approach has encouraged many women to share their health problems with the doctors. Women in the community go for examination on the camp day, they get support from each other. Such camps where women are properly examined with due privacy and care, help change the norm in the community where unnecessary modesty prevents early diagnosis of many reproductive illnesses and proper management of such problems”. During FGD with males in Jumla, some respondents, however, had slightly different opinion regarding mobile camps. They compared camps with catering services and buffet party during picnic, weeding ceremony and feasts. They said that one can see and get service everything for three days and nothing would remain after the camps. Their concern was to address the basic needs and promote sustain health, and strengthen the existing health facilities in the districts.

\section{4 | Madhusudan Subedi}

A 44 years old woman from Bajura, who had undergone surgery six month ago in NMCTH told, "I had been suffering from white discharges and lower abdominal pain for 15 years, a long time. I was very shy to discuss this with anyone until I heard them broadcast about the free health camps on the radio. Even though I was initially reluctant to share my problems with the person at registration (since he was a male), I gathered enough courage to tell him my problem. The female doctor was open, polite and assuring, and listened to all my problems patiently and prescribed me the medication along with clear instructions about how and when to use them. And here I am today, all healthy and happy with no such problems whatsoever."

In this approach special resources are mobilized for a short time periodically rather than provide high level services continuously in rural areas. In a camp or campaign, the health staff at a local health facility was found to be active and willing to put extra efforts and work as a team. Higher level services also attract the community as they see more value in less time and effort.

Learning experiences from the camp approach are that it is a very short term activity and the issue of sustainability is questionable. Camps should be run on a more routine and regular basis, and also be smaller so that better quality of services can be ensured. The community should also know in advance that the camp activity will take place on a fixed day of the month. This would enable people to plan to go to the camp, the number of clients would probably be less and thus giving more time for individual attention of the clients. The cost of the camps will also be reduced because many of the services become routine with little outside input.

Medicine like vaginal tablets and higher antibiotics were given to the women from the camp pharmacy. Such medicines are not available in the health facilities, and are not included as essential medicine. During the interaction with the women, they told that they later bought the same medicine with the help of the prescription paper provided during the mobile camps, often with the help of their relatives and friends who had gone to district headquarters or to Nepalganj. The women did this because the medicines were effective, but were not available at the local health 


\section{6 | Madhusudan Subedi}

facility. Thus, the camp approach has accelerated the medication process in the remote areas.

\subsection{Body Politics: Barriers to Accessing Care}

Until recently, social and political theory and scholarship tended to ignore the human body, placing emphasis upon social structure and individual subjectivity with little discussion of where corporality of the 'lived body' fitted in (Lupton, 2003). One reason for the reluctance to theorize or historically position the body, in my view, was the desire of scholars in humanities and social sciences to 'avoid' the biological determinism of the hard human sciences. As a result, for decades, macro-sociologists have tended to focus on the 'social system', the structural, political and economic dimensions of social control, a theoretical space in which the body disappeared from view, while micro-sociologists were concerned with individual behavior as socially constituted, but neglected considerations of the embodiment of decision making. How individuals can regulate themselves and control their bodily deportment is the central concern of this paper.

Foucault (1979) identifies the establishment of medical clinics and teaching hospitals in the late eighteenth century as a pivotal point for conceptualizing the body. In The Birth of the Clinic (1975) Foucault refers that medical practices changed in the eighteen century; the introduction and routine adoption of physical examination, the post-mortem, the stethoscope, the microscope, the development of discipline of anatomy, psychiatry, radiology, and surgery, the institutionalization of the hospital and the doctor's surgery, all served to increasingly exert power upon the body. At the same time, bodies were subjected to increased regulation, constant monitoring, discipline and surveillance in other spheres, most notably the prison, the school, the asylum, the military, and the workshop. The medical encounter began to demand that patients reveal the secrets of their bodies, both by allowing physical examination and by giving their medical history under questioning by the doctors. The patients had to speak, to confess, to reveal; illness was transformed from what is visible to what was heard.
For Foucault, the medical encounter is a supreme example of surveillance, whereby the doctor investigates, questions, touches the exposed flesh of the patient, while the patient acquiesces, and confesses, with little knowledge of why the procedures are carried out. The body is rendered an object to be prodded, tested and examined. The owner is expected to give up his or her jurisdiction of the body to the doctor. The sexually active body is currently a primary site at which contesting discourses compete for meaning, particularly in the field of medicine and public health (Lupton, 2003).

Most people in Nepal are socialized at a very early age into society's dictates concerning the situations, circumstances, and purposes of allowable and unallowable genital exposure. Specially, females are socialized into rigorous norms concerning society's expectations in the covering and privacy of specified areas of her body, especially her genital part. Even for a woman who has overcome being bothered by genital exposure in the presence of her sexual partner, this problem frequently recurs when she is expected to expose her vagina in a nonsexual manner to a male. Such is the case with vaginal examination (Henslin and Biggs, 1991) during RH check up. The vaginal examination can become so threatening, in fact, that for many women it not only represents a threat to their feelings of modesty, but also threatens their person and feelings of who they are. The reason is that through learning about taboos, emotions often are associated with the genital area, thus nudity and undressing in front of strangers are problematic for the patient. Clothing is considered as an extension of the self, and in some cases the clothing comes to represent the particular part of the body that it covers. In this case, this means that panties and girdles represent to women their 'private area'. Conceptualizing the vagina as a sacred object yields a perspective that appears to be of value in analyzing vaginal examination. Sacred objects are surrounded by rules protecting the objects from being profaned, rules governing who may approach the sacred, under what circumstances it may be approached, and what may and may not be done during such an approach (Durkheim, 1995). If these rules are followed, the sacred will not lose any of its sacredness, but if they are violated, there is danger of the sacred being profaned. 
In conceptualizing the vagina in this way, who may and who may not approach the vagina is highly circumscribed, with the primary person so allowed being one who is ritually related to the possessor of the vagina, the husband (Henslin and Biggs, 1991). It is perhaps because they have profaned the sacred that prostitutes usually lack respect. And in doing so, not only have they failed to limit vaginal access to culturally prescribed individuals, they have added further violation by allowing vaginal access on a pecuniary basis. They have, in effect, sold the sacred (Henslin and Biggs, 1991).

Uterine Prolapse is a complex condition that is often kept in secret because of the shame of the condition affecting a sensitive part of the woman's body. Many women fear condemnation from their communities and families, discussion and the debate surrounding the disease does not openly occur within the family and in society. Women who suffer from Uterine Prolapse continue to remain silent about the matter. This modality is not the ultimate solution of the problem. A woman having Second Degree Prolapse in Salyan, said, "How could I tell others? It's such a shameful thing”. A FCHV from the same health facility mentioned, "Many women in the village are living with such problems for more than 30-40 years. They cannot tell about their problems to doctors, but just say they have pain in lower abdomen and turn their heads down. If a doctor is not experienced, he/she would not be able to diagnose the real problem. During the camp observation and in-depth interview with FCHV in Achham it was found that these persons had difficulty to share UP problems with the local health workers. The doctor at the camp told that FCHV who was suffering from UP problems could not share her problem directly with the doctors. When the doctor asked her to examine her uterus, she did not give permission. After an hour's consulting and detailed checking of the body, she was diagnosed with a second degree prolapsed uterus.

The study findings of Institute of Medicine and UNFPA (2006) revealed that 46.97 percent waited for fifteen to thirty years before seeking treatment in a hospital. Such long time to seek treatment is due to deep rooted socio-cultural phenomena regarding UP. The women who know the place of treatment and have the means to access it, hesitate due to fear of divorce or abandonment; isolation, shame and sensitivity surrounding genital issues; traditional belief

\section{8 | Madhusudan Subedi}

that hysterectomies will lead to weakness, and lack of emotional support.

Many women face obstacles in receiving necessary follow-up care, particularly as needed in the case of pessary rings, which requires periodic replacement by a medical practitioner and maintenance to avoid infection. Discussions with prolapsed women in Salyan and Achham, and with the camp team, revealed that some women had been using the same ring for more than 2 years, and consequently developed an infection. They had inserted ring pessary during the camps or at the tertiary care centre but were not aware about its proper management. They were hesitant to talk about the ring with the health workers at the local health facility. At the same time local health workers did not know that the particular women had inserted ring pessary.

\section{Conclusion}

Although UP is not an immediately life threatening condition, it seriously hampers the life quality of those who are affected. For women living with UP life's basic activities are challenged. Urinating, defecating, walking, standing, sitting, and sexual intercourse can be difficult and painful. This, in turn, leads to various forms of psychosocial and physical impairments. It is crucial for women's health and well-being to not make the indication for surgery lightly. Surgical management of advanced stages of UP cannot be a substitute for preventive measures. Extensive information and preventive programs, as well as early management of genital prolapse should be the first to reduce this significant social and public health problem in Nepal. A substantial shift from humanitarian aid to a more sustainable public health intervention, strengthen the existing health facilities in the districts and regions, is urgent. Similarly, there is a need to assess the health related quality of life that can be gained through UP surgery intervention. At the same time, inter-disciplinary research, combining biomedical and social science methods should be promoted so that epidemiological information as well as a clear understanding of the context in which health problems arise can be obtained. 


\section{Acknowledgements}

This article is a revised version of a paper that was presented at the International Conference in Kathmandu (April 5-6, 2010) on "Education, Gender and Development", organized jointly by Tribhuvan University, Liverpool John Moores University, and University of Dhaka. I would like to thank Marit Bakke, Shambhu Upadhyay, Sara Parkar and Rose Khatry for their valuable feedback and suggestions. I am alone responsible, however, for the paper and issues presented.

\section{References}

Bodner-Adler, Barbara, Chanda Shrivastava and Klaus Bodner (2007). Risk Factors for Uterine Prolapse in Nepal. International Urogynecology Journal, 18:1343-1346.

Bonetti, Tiphaine, Anne Erpelding and Laxmi Raj Pathak (2004). Listening to "Felt Needs": Investigating Genital Prolapse in Western Nepal. Reproductive Health Matters, 12 (23):166-175.

Dangal, Ganesh (2008). A Study of Reproductive Morbidity of Women in Eastern Terai Region of Nepal. Nepal Journal of Obstetrics and Gynecology, 3(1):29-34.

Durkheim, Emile (1995). The Elementary Forms of Religious Life. Translated by Karen Fields. New York: Free Press.

Foucault, M. (1979). The History of Sexuality, Volume One: An Introduction. London:Penguin.

Foucault, M. (1975). The Birth of the Clinic: an Archaeology of Medical Perception. New York, NY: Vintage Books.

Henslin, James M. and Mae A. Biggs (1991). The Sociology of Vaginal Examination. In James M. Henslin (ed.) Down to Earth Sociology. New York: The Free Press.

Institute of Medicine and UNFPA (2006). Status of Reproductive Morbidities in Nepal. Kathmandu: Report Submitted to UNFPA.

Inhorn, Marcia C. (2006). Defining Women's Health: A Dozen Messages from More than 150 Ethnographies. Medical Anthropology Quarterly, 20 (3) 345-378.

Lupton, Deborah (2003). Medicine as Culture. London: SAGE Publication.

\section{0 | Madhusudan Subedi}

Marahatta, RK and Arati Shah (2003). Genital Prolapse in Women of Bhaktapur. Nepal Medical College Journal, 5(1):31-33

MoHP, New ERA and Macro Int'l (2007). Nepal Demographic and Health Survey 2006. Kathmandu: MoHP, New ERA and Macro Int'l.

Pradhan, Ajit, Bal Krishna Subedi, Sarah Barnett, Sharad Kumar Sharma, Mahesh Puri, Pradeep Poudel, Sovana Raj Chitrakar, Naresh Pratap KC and Louise Hulton (2010). Nepal Maternal Mortality and Morbidity Study 2008/2009. Kathmandu: Family Health Division, Ministry of Health and Population.

Schaaf, Jelle, Anjana Dongol and Loes van der Leeuw-Harmsen (2007). International Urogynecology Journal, 6:851-855.

Subedi, Madhusudan (2001). Medical Anthropology of Nepal. Kathmandu: Udaya Books.

Uberoi, Patricia (1996). When is a marriage not a marriage? Sex, sacrament and contract in Hindu marriage. Contributions to Indian Sociology: Occasional Studies 7: 319-345.

UNFPA and Sancharika Samuha (2007). Booklet on Uterine Prolapse. Kathmandu: Sancharika Samuha. 